\title{
Predicting Suicidal Ideation in Adolescent Boys and Girls: The Role of Psychological Maturity, Personality Traits, Depression and Life Satisfaction
}

\author{
Fabia Morales-Vives and Jorge Manuel Dueñas
}

Research Center for Behavior Assessment. Universitat Rovira i Virgili (Spain).

\begin{abstract}
In recent years, suicide rates have increased in adolescents and the young population, so these age groups are considered as populations at risk. Considering that suicidal ideation is the first sign of possible future suicide behavior, the objective of this study is to determine the relative importance of psychological maturity, personality, depression and life satisfaction in predicting suicidal ideation in adolescents. Results show that depressive symptoms is the variable that best predicts suicidal ideation, but psychological maturity, life satisfaction and emotional stability are predictors as well $\left(R^{2}=.51, p<.001\right)$. However, the Multigroup Structural Equation Models analyses carried out show that emotional stability has an indirect relationship with suicidal ideation, through its relationship with depressive symptoms, life satisfaction and identity. Two Multigroup Structural Equation Models were proposed to better understand the relationships between these variables for each sex. The results show that the fit of the model that includes the variable Self-reliance is better for boys than for girls (chi-square contributions of 8.175 for girls and 1.978 for boys) unlike the other model (chi-square contributions of 0.288 for girls and 1.650 for boys). These results suggest that the psychological maturity subscale Self-reliance play a role in suicidal ideation in males but not in females. Although there have been no previous studies on the role of psychological maturity as a predictor of suicidal phenomena, the current study suggests that it is a feature to be considered in the prediction of adolescent suicidal ideation.
\end{abstract}

Received 1 February 2016; Revised 19 March 2018; Accepted 20 March 2018

Keywords: adolescence, depression, personality, psychological maturity, suicidal ideation.

According to the World Health Organization, every year almost one million people die by suicide around the world, and it is the second leading cause of death in the 15 to 19 years age group (World Health Organization, 2012). Therefore, suicide is regarded as a major public health problem worldwide that generates a considerable psychosocial impact, and has social, economic and emotional consequences. According to Park (2013), identification of factors associated with suicidal ideation may help health professionals to provide early interventions to those at risk and to lower the suicide rate.

There is a continuum of severity in suicidal behavior, in which suicidal ideation is the least severe form of suicidal phenomena. The subsequent forms would be suicidal threats, suicidal attempts and, finally, completed suicide, even though not all cases would be consistent with this hierarchical model. Suicidal ideation consists of thoughts about ending one's life, although they might not necessarily lead to a suicide. However, suicidal ideation would be the first sign of possible

Correspondence concerning this article should be addressed to Fabia Morales-Vives. Universitat Rovira i Virgili. Facultat de Ciències de l'Educació i Psicologia. Campus Sescelades. Carretera de Valls s/n. 43007 Tarragona (Spain).

E-mail: fabia.morales@urv.cat Telephone: +34-977558086. Fax: +34-977558088. future suicidal behavior (Nock et al., 2008). In fact, according to Miranda, Ortin, Scott, and Shaffer (2014), thinking about suicide often, seriously, and for a long time is associated with a future suicide attempt. Furthermore, some longitudinal studies in children and adolescents, such as the one by Pfeffer, Lipkins, Plutchick, and Mizruchi (1988), show that suicidal ideation is characterized by its temporal stability, which is another reason for concern. On the other hand, suicidal ideation and suicidal behavior correlates might be somewhat different so both must be studied (e.g., Heisel et al., 2006).

Suicide ideation is a multifaceted issue that involves bio-psychosocial and cultural factors. As Park (2013) pointed out, suicidal ideation precedes suicidal acts, so the identification of predictors of ideation might lead to a better understanding of suicide risk, and it may help to prevent suicide. For this reason, the current study focuses on identifying individual characteristics that predict suicidal ideation in adolescents. More specifically,

How to cite this article:

Morales-Vives, F., \& Dueñas, J. M. (2018). Predicting suicidal ideation in adolescent boys and girls: The role of psychological maturity, personality traits, depression and life satisfaction. The Spanish Journal of Psychology, 21. e10. Doi:10.1017/sjp.2018.12 
the personal characteristics addressed in the present study are psychological maturity, life satisfaction, depression and personality traits, because few studies have analyzed the relationship between these variables and suicidal ideation, despite their importance during adolescence.

\section{Suicidal ideation predictors}

A large number of factors related to suicidal ideation have been identified, including individual characteristics, family and social factors. Regarding individual characteristics, numerous studies suggest that depressive symptoms are one of the main predictors for both ideation and suicidal behavior in adolescents (e.g., Lasgaard, Goossens, \& Elklit, 2011; Viñas, Canals, Gras, Ros, \& Domènech-Llaberia, 2002). According to Hintikka et al. (2009), a depressive mood is considered a necessary condition for the occurrence of suicidal ideation. Between 10 and $15 \%$ of patients with major depression commit suicide, and about two-thirds of the total show suicidal ideation (Erroteta \& Rodrigo, 2013). For this reason, the studies focused on the prediction of suicidal phenomena must assess depressive symptoms.

Another factor that has been linked to suicidal ideation is subjective wellbeing (e.g., Heisel \& Flett, 2004; Inder et al., 2014). As Heisel and Flett (2004) showed, there is a negative correlation between life satisfaction and some negative psychological factors such as depression and neuroticism. However, life satisfaction explains significant additional variability in suicidal ideation scores above and beyond that accounted for by depression and neuroticism (Heisel \& Flett, 2004). Two components have been identified within subjective wellbeing: an emotional component and a cognitive component. The emotional component is related to people's emotional evaluations of their lives, and it is defined as the balance of pleasure and displeasure in people's lives (Schimmack, Schupp, \& Wagner, 2008). The cognitive component has been called life satisfaction and is defined as the overall assessment that someone makes of his/her life on the basis of the fit between personal goals and achievements (Koivumaa-Honkanen et al., 2001). The cognitive component is moderately correlated with the emotional component, and has a different correlation pattern with other variables. Therefore, these components should be assessed separately. However, many of the measures of subjective wellbeing do not differentiate between them. Few studies have specifically analyzed the relationship between suicidal ideation and the cognitive component of subjective wellbeing (in other words, life satisfaction). These studies suggest that this variable is a predictor of suicidal ideation in both adults (e.g., Amer \& Hamdan-Mansour, 2014;
Koivumaa-Honkanen et al., 2001) and adolescents (e.g., Park, Koo, \& Schepp, 2005). Goldbeck, Schmitz, Besier, Herschbach, and Henrich (2007) found that life satisfaction decreases during adolescence in both males and females so it might be particularly relevant in this period of life. In fact, adolescence is a developmental stage characterized by numerous changes at various levels that can generate a considerable amount of stress. This might explain the decrease in life satisfaction, which in turn could have an effect on suicidal ideation.

Several authors have found significant correlations between personality and suicidal ideation in adolescents (e.g., Fergusson, Woodward, \& Horwood, 2000) and young adults (e.g., Kerby, 2003; Velting, 1999). Although the most popular model of personality in recent decades has been the Five Factor Model, relatively little research has been done to determine the relevance of the Big Five personality traits in the prediction of suicidal ideation. Moreover, the results of these studies have been contradictory. In general, the studies suggest that emotional stability is related to suicidal ideation (e.g., Chioqueta \& Stiles, 2005; DeShong, Tucker, O'Keefe, Mullins-Sweatt, \& Wingate, 2015; Fergusson et al., 2000; Kerby, 2003; Velting, 1999). According to Valois, Zullig, and Hunter (2015), emotional stability is an important variable because emotional self-efficacy can help adolescents overcome risk factors that can trigger the transition from emotional crisis to suicidality. However, there is less agreement about the relevance of other personality traits. Several studies show a relationship between suicidal ideation and low Extraversion (DeShong et al., 2015), but only few show a relationship with low Conscientiousness (Velting, 1999; Kerby, 2003), low Agreeableness (Kerby, 2003), and high Openness to experience (Chioqueta \& Stiles, 2005). It should be taken into account that some studies do not control depressive symptoms (e.g., DeShong, Tucker, O'Keefe, Mullins-Sweatt, \& Wingate, 2015; Kerby, 2003), which could lead to misleading results because depression is related to personality (Klimstra, Akse, Hale III, Raaijmakers, \& Meeus, 2010) and also to suicidal ideation, especially emotional stability (Kotov, Gamez, Schmidt, \& Watson, 2010). Personality may have an indirect effect on suicidal ideation through its relationship with depression and depressive symptoms, as the study carried out by VrshekSchallhorn, Czarlinski, Mineka, Zinbarg, and Craske (2011) suggests. In fact, De Man and Leduc (1995) showed that many variables are no longer associated with suicidal ideation when depression is controlled. For this reason, the effect of this variable on suicidal ideation needs to be taken into account if it is to be determined whether personality has a direct or an indirect effect. 


\section{Psychological maturity}

There have been no previous studies on the possible role of psychological maturity as a predictor of suicidal ideation during adolescence, although several studies suggest that adolescents with low maturity tend to show lower emotional stability (Morales-Vives, Camps \& Lorenzo-Seva, 2013) and more problematic behaviors (Cauffman \& Steinberg, 2000). In general, as adolescents become more mature, antisocial behaviors, sexual risk behaviors and alcohol abuse tend to diminish, and they display greater control over their impulses, more planning, greater autonomy and greater resistance to peer group pressure.

In this paper we will use the definition of maturity put forward by Greenberger (1984): it is the ability to take on obligations and make responsible decisions, taking into consideration one's own characteristics and needs and accepting the consequences of one's own actions. This definition refers specifically to the individual adjustment proposed by Ellen Greenberger and her colleagues within their model of psychosocial maturity, which is divided into three different components: Work orientation, Self-reliance and Identity. Work orientation is defined as the individual's willingness to fulfill his or her own obligations (for example, adolescents begin to do their homework and do not stop until they finish). Self-reliance is defined as a person's willingness to take the initiative, without allowing others to exercise excessive control. And finally, Identity is defined as the adolescent's knowledge of him or herself. Adolescents must define their own values and identify their characteristics and needs if they want to carry out a future project (for example, decide whether to study for a degree or not, and, if so, which one). The construction of a coherent sense of personal identity is considered one of the main challenges of adolescence because it is a transitional phase of life full not only of stress and strife, but also of personal growth to cope with the increasing demands (Sood \& Gupta, 2014). Several studies show that there is a relationship between Identity and Neuroticism (Klimstra, Luyckx, Goossens, Teppers, \& De Fruyt, 2013; Morales-Vives et al., 2013), which suggests that identity formation is facilitated by low levels of Neuroticism (Klimstra et al., 2013). Moreover, identity confusion is also related to higher levels of depression (Schwartz et al., 2011). In fact, according to Schwartz (2007), a coherent sense of personal identity protects against indicators of distress such as anxiety and depression. However, a coherent sense of personal identity and a personal growth initiative are related to positive outcomes such as subjective wellbeing and life satisfaction (Christiansen, Backman, Little, \& Nguyen, 1999; Sood \& Gupta, 2014).

\section{Gender differences in adolescence}

Some studies show that suicidal ideation is more common in females than males (e.g., Park, 2013). According to Allison, Roeger, Martin, and Keeves (2001), when depression is moderate, females tend to show higher levels of suicidal ideation than males. Furthermore, gender differences have been found in the risk factors associated with suicidal ideation. For this reason, authors such as Park et al. (2005) claim that using gender to explain the difference in risk factors may improve our understanding of suicidal ideation. The factors identified in females include low self-esteem (Kelly, Lynch, Donovan, \& Clark, 2001), smoking and economic status (Park et al., 2005), while the factors identified in males are chronic stress (Wannan \& Fombonne, 1998) or lack of communication with friends or family (Park et al., 2005). Variables such as depression, life satisfaction, emotional stability, substance abuse or disturbed parental relationships are predictors for both genders (Kerby, 2003; Pitman, Krysinska, Osborn, \& King, 2012; Valois, Zullig, Huebner, \& Drane, 2004; Wannan \& Fombonne, 1998). However, the relevance of some of these variables as predictors can depend on gender. For example, depression and drug use are stronger predictors of suicidal ideation in females than in males (Kandel, Raveis, \& Davies, 1991; Park et al., 2005). Therefore, it is important to identify gender differences in suicidal ideation and behavior, because this knowledge may help to design prevention and intervention programs that respond to the needs of both boys and girls.

The overall goal of this study is to determine the relative importance of psychological maturity, personality, depression and life satisfaction in the prediction of suicidal ideation in adolescent boys and girls. For this reason, the first objective of this study is to determine if these variables are predictors of suicidal ideation, in which case they will be significantly correlated with suicidal ideation. More specifically, on the basis of the results of previous studies, we expect depressive symptoms, life satisfaction, emotional stability and extraversion to be related to suicidal ideation. More specifically, we expect that higher levels of depressive symptoms and lower levels of life satisfaction, emotional stability and extraversion to be related to higher levels of suicidal ideation. We also expect psychological maturity to predict suicidal ideation, specially the subscales Identity and Self-reliance, because adolescents with low maturity tend to show lower emotional stability (Morales-Vives et al., 2013) and more problematic behaviors (e.g. Cauffman \& Steinberg, 2000). In other words, we expect low levels of psychological maturity, and more specifically low levels of Self-reliance and Identity, to be related to higher levels of suicidal ideation. 
The second objective of this study is to test whether emotional stability is indirectly related to suicidal ideation, through its relationship with other variables. As has been mentioned before, previous studies have suggested that emotional stability is indirectly related to suicidal ideation thorough its relationship with depression (Vrshek-Schallhorn et al., 2011). However, in the current study we aim to determine if this indirect relationship is also due to the relationship that emotional stability has with other variables, more specifically with life satisfaction, identity and self-reliance. Previous studies show that a high level of emotional stability is related to lower levels of depression and higher levels of life satisfaction, so emotional stability is considered to be a greater predictor of both happiness and life satisfaction (Heisel \& Flett, 2004; Hills \& Argyle, 2001). Other studies show that identity is related to both emotional stability (Klimstra et al., 2013; Morales-Vives et al., 2013) and depression (Schwartz et al., 2011), because a coherent sense of personal identity protects against indicators of distress such as anxiety and depression (Schwartz, 2007). Moreover, according to Klimstra et al. (2013), emotional stability facilitates identity formation. For this reason, we expect an indirect relationship between emotional stability and suicidal ideation, through its relationship with depressive symptoms, identity, life satisfaction and self-reliance.

Another goal is to assess gender-related differences in suicidal ideation predictors, especially in psychological maturity subscales because there are no previous studies on this subject. However, on the basis of previous studies, we did not expect to find gender-related differences in the association of suicidal ideation with depressive symptoms, emotional stability and life satisfaction predictors (Valois et al., 2004; Wannan \& Fombonne, 1998), although there could be gender differences in the subscales of psychological maturity. For this reason, we also aim to determine whether the model we propose to predict suicidal ideation fits boys and girls equally well or whether there are sex-associated differences in the fit.

\section{Method}

\section{Participants}

The sample consisted of 365 adolescents (157 males and 208 females) recruited from two state schools in the province of Tarragona (Spain). One of these schools was located in a city and the other one in a country village, in order to have a heterogeneous sample with students from different socioeconomic backgrounds. The age range of the subjects was 15 to 19 years, with a mean of $16.81, S D=0.99 .26 .5 \%$ of students were studying the fourth year of lower-secondary education, $36.4 \%$ were studying the first year of upper-secondary education and $37.1 \%$ the second year of upper-secondary education.

\section{Measures}

Scale for Suicide Ideation (SSI) (Beck, Kovacs \& Weissman, 1979). We used the self-administered version of the SSI questionnaire developed by Villardón (1993). It is a 10-item self-report version in Spanish, with suitable psychometric properties. Participants needed about 5 minutes to complete the questionnaire. The internal consistency in our sample was .89. Each item consists of four statements that reflect various levels of suicidal ideation. This self-administered version is unifactorial and specifically refers to the desire for suicide.

Beck Depression Inventory (BDI) (Beck, Ward, Mendelson, Mock, \& Erbaugh, 1961). We used the Spanish adaptation of this questionnaire, which has suitable psychometric properties. The internal consistency in our sample was .86. The questionnaire has 21 items and each item consists of four statements that reflect various levels of depressed feelings. Participants needed between 5 and 10 minutes to complete the questionnaire. Item 9 assesses suicidal ideation, so this item was excluded in the computation of the overall scores of BDI, in order to avoid any overlap with the measure of suicidal ideation in SSI, which would lead to an overestimation of the correlation between depressive symptoms and suicidal ideation.

Overall Personality Assessment Scale (OPERAS) (Vigil-Colet, Morales-Vives, Camps, Tous, \& LorenzoSeva, 2013). This questionnaire is based on the Big Five personality factors model and assesses the following factors: Extraversion, Agreeableness, Conscientiousness, Emotional stability, and Openness. It consists of 40 items answered on a five-point Likert scale: (1) Fully disagree, (5) Fully agree. Therefore, it is a short measure, so adolescents need about 10 minutes to complete the questionnaire. The test has suitable psychometric properties. We found the following internal consistencies: .86, .71, .77, .86 and .81 for Extraversion, Agreeableness, Conscientiousness, Emotional stability and Openness, respectively. This questionnaire contains four items of social desirability, with the purpose of controlling this response bias. In fact, this questionnaire was developed by Vigil-Colet et al. (2013) using the procedures proposed by Ferrando, Lorenzo-Seva, and Chico (2009) and Lorenzo-Seva and Ferrando (2009) to control two response biases: social desirability (SD) and acquiescence (AC). The first step in the procedures is to identify a factor related to SD by using the four items that are markers of SD. Then, the inter-marker correlation matrix is used to define a SD factor which, in turn, is used to compute the loading values of the content items on the SD factor. The next step is to 
remove the variance explained by the SD factor, which leads to an inter-item residual correlation matrix with no SD effects. Then, as the questionnaire has positively and negatively worded items, the method developed by Lorenzo-Seva and Ferrando (2009) is used to remove the variance due to acquiescent responding. As a consequence, this questionnaire provides individuals' scores free of SD and AC, because the factor scores are calculated using the loadings obtained in the development of the questionnaire, after the implementation of these procedures.

Satisfaction with Life Scale (SWLS) (Diener, Emmons, Larsen, \& Griffin 1985). The Spanish adaptation of the SWLS has suitable psychometric properties, and the internal consistency in our sample was .83. It is a unifactorial questionnaire answered on a five-point Likert scale: (1) Strongly disagree, (5) Strongly agree. The SWLS is a short 5-item instrument, so it usually requires only about one minute of a respondent's time.

Psychological Maturity Assessment Scale (PSYMAS) (Morales-Vives et al., 2013). This questionnaire is a 26-item self-report instrument, and each item is answered on a five-point Likert scale: (1) Fully disagree, (5) Fully agree. In general, adolescents need about 10 minutes to complete the questionnaire. Psychological maturity is defined as the ability to take on obligations and make responsible decisions, bearing in mind one's own characteristics and needs and accepting the consequences of one's own actions. It contains the scales Work orientation, Self-reliance and Identity, previously explained. This questionnaire has suitable psychometric properties. We found the following internal consistencies: .71 for Work orientation, .78 for Self-reliance and .77 for Identity. The reliability of the overall scale is .82. This questionnaire corrects the social desirability and acquiescence biases using the procedures proposed by Ferrando et al. (2009) and Lorenzo-Seva and Ferrando (2009), as in the questionnaire OPERAS.

\section{Procedure}

The participants were recruited from two state high schools. This study was approved by the institutional review board, and we also provided the headmasters of the two high schools with information about it. We sent parental permission forms to all parents of students approximately three weeks before data collection and asked parents to sign and return them if they wanted their child to participate in the study. A total of $79.4 \%$ of parents gave their consent, so the remaining $20.6 \%$ of adolescents were excluded because their parents had not given their consent, or because they had not returned the form. The questionnaires were administered collectively during regular school hours, and students were guaranteed anonymity and confidentiality. We told the students that participation was voluntary, and that they could refuse to participate at any moment.

We performed descriptive analysis, correlations and multiple regression analysis to assess the predictive value of the different variables on suicidal ideation. Statistical analyses were carried out using SPSS V.22, MPlus v6.1 and the MIMR-Raw.sps program developed by Lorenzo-Seva, Ferrando and Chico (2010). MIMR-Raw.sps runs automatically from the SPSS syntax window, and the output can be configured in a variety of ways. As well as the indexes included in SPSS, the program also provides additional indices to augment the interpretation of multiple regression: Structure coefficients, and Johnson's relative weights (Johnson, 2000). In fact, standardized coefficients (also known as beta weights) are context dependent and often do not work well for explanatory purposes, especially in the presence of substantially correlated predictors, in which case they can also become very unstable (Johnson, 2000). For this reason, it is advisable to use additional indexes to assess the relative importance of the predictors. Johnson's relative weights, for example, estimate the relative contribution each variable makes to the prediction of a dependent variable, taking into account both its unique contribution and its contribution when combined with other variables. MIMR-Raw. sps provides the relative weights as percentages (i.e., they are divided by $R^{2}$ and multiplied by 100 ). On the basis of the results obtained in the multiple regression analyses, we also fitted two multiple-group structural equation models to gain a better understanding of the relationship between the variables for boys and girls. It should be taken into account that structural equation models allow both confirmatory and exploratory modeling (Marsh, Morin, Parker \& Kaur, 2014). The models were falsifiable, so the appropriateness of the proposed path-relations network can be tested simultaneously in both groups. Models were fitted using maximum likelihood estimation as implemented in the program MPlus v6.1. Model-data fit was assessed by using the following goodness-of-fit indices: the $\chi^{2}$-test, Comparative Fit Index (CFI), Tucker-Lewis Index/Non normed fit index (TLI), Root Mean Square Error of Approximation (RMSEA) and Standardized Root Mean Square Residual (SRMR). Values of CFI and TLI $\geq 0.95$, and a value of SRMR less than .08 are indicative of relatively good fit (Hu \& Bentler, 1999). RMSEA indices close to .06 or a stringent upper limit of .07 are also indicative of relatively good fit (Hu \& Bentler, 1999; Steiger, 2007).

\section{Results}

Table 1 shows the descriptive statistics for the measures across the whole sample, boys and girls. As can 
Table 1. Descriptive Statistics for the Whole Sample, Boys and Girls

\begin{tabular}{|c|c|c|c|c|c|c|}
\hline \multirow[b]{2}{*}{ Variable } & \multicolumn{2}{|l|}{ All } & \multicolumn{2}{|l|}{ Boys } & \multicolumn{2}{|l|}{ Girls } \\
\hline & $M$ & $S D$ & $M$ & $S D$ & $M$ & $S D$ \\
\hline Suicidal ideation & 15.73 & 3.87 & 15.35 & 3.67 & 16.01 & 4.00 \\
\hline Depressive symptoms & 28.11 & 7.02 & 27.29 & 7.15 & 28.73 & 6.87 \\
\hline Life satisfaction & 18.19 & 3.95 & 18.36 & 4.14 & 18.05 & 3.80 \\
\hline Work orientation & 48.47 & 9.88 & 48.37 & 9.62 & 48.55 & 10.01 \\
\hline Self-reliance & 46.83 & 11.45 & 46.33 & 12.64 & 47.21 & 10.48 \\
\hline Identity & 49.92 & 11.11 & 50.54 & 11.20 & 49.45 & 11.04 \\
\hline Overall Maturity & 47.95 & 10.65 & 48.01 & 10.99 & 47.89 & 10.41 \\
\hline Extraversion & 50.35 & 9.13 & 50.06 & 9.37 & 50.56 & 8.96 \\
\hline Agreeableness & 47.97 & 9.39 & 47.10 & 10.29 & 48.63 & 8.61 \\
\hline Conscientiousness & 44.17 & 9.67 & 43.39 & 9.50 & 44.76 & 9.78 \\
\hline Emotional stability & 48.27 & 9.52 & $50.88^{* *}$ & 10.02 & $46.31^{* *}$ & 8.65 \\
\hline Openness to experience & 47.64 & 11.20 & $44.95^{* *}$ & 11.50 & $49.66^{* *}$ & 10.55 \\
\hline
\end{tabular}

Note: ${ }^{* *} p<.01 .{ }^{*} p<.05$.

be seen, boys have higher scores than girls on emotional stability, $t_{(363)}=4.67 p<.01$ Effect size: $d=0.49$; and girls have higher scores on Openness to experience, $t_{(363)}=-4.07 p<.01$ Effect size: $d=0.43$; but there were no differences in other scales.

The correlations between age and the study variables are shown in Table 2. Age had no significant correlations with the other variables. Most of the correlations among the study variables were statistically significant. In fact, all the study variables except openness to experience had significant correlations with suicidal ideation. Depressive symptoms had a positive correlation with suicidal ideation, but maturity measures, life satisfaction, emotional stability, extraversion, agreeableness and conscientiousness had negative correlations.
A multiple regression analysis was carried out using the program MIMR-Raw.sps. The Big Five subscales, Psychological maturity subscales, and Depression and Life satisfaction scales were entered into the regression equation as potential predictors of suicidal ideation. Table 3 shows the standardized regression coefficients (Beta) obtained, the structure coefficients and the Johnson's relative weights for the overall sample. The $R^{2}$ was $.51(F=36.2, p<.001)$ and the $95 \%$ confidence interval was .41 and .61. Only three predictors (Depressive symptoms, Life satisfaction and Identity) turned out to have a significant Beta $(p<.01)$ and also significant structure coefficients. Although the Beta of emotional stability was not significant, the fact that the Johnson's relative weight was significant suggests that it should be included in the model as well, because it contributes

Table 2. Correlation Matrix between Variables.

\begin{tabular}{|c|c|c|c|c|c|c|c|c|c|c|c|c|}
\hline & 1 & 2 & 3 & 4 & 5 & 6 & 7 & 8 & 9 & 10 & 11 & 12 \\
\hline \multicolumn{13}{|l|}{ 1. Age } \\
\hline 2. Suicidal ideation & -.11 & & & & & & & & & & & \\
\hline 3. Depressive symptoms & .01 & $.68^{* *}$ & & & & & & & & & & \\
\hline 4. Life satisfaction & .02 & $-.48^{* *}$ & $-.51^{* *}$ & & & & & & & & & \\
\hline 5. Work orientation & -.02 & $-.18^{* *}$ & $-.21^{* *}$ & $.24^{* *}$ & & & & & & & & \\
\hline 6. Self-reliance & .06 & $-.13^{*}$ & -.08 & $.12^{*}$ & $.20^{* *}$ & & & & & & & \\
\hline 7. Identity & .06 & $-.53^{* *}$ & $-.56^{* *}$ & $.55^{* *}$ & $.30^{* *}$ & $.28^{* *}$ & & & & & & \\
\hline 8. Overall Maturity & .06 & $-.41^{* *}$ & $-.42^{* *}$ & $.44^{* *}$ & $.60^{* *}$ & $.72^{* *}$ & $.79^{* *}$ & & & & & \\
\hline 9. Extraversion & -.03 & $-.21^{* *}$ & $-.25^{* *}$ & $.24^{* *}$ & -.06 & .10 & $.42^{* *}$ & $.26^{* *}$ & & & & \\
\hline 10. Agreeableness & -.04 & $-.18^{* *}$ & $-.17^{* *}$ & $.24^{* *}$ & .00 & .08 & $.29^{* *}$ & $.20^{* *}$ & $.12^{*}$ & & & \\
\hline 11. Conscientiousness & .09 & $-.21^{* *}$ & $-.22^{* *}$ & $.27^{* *}$ & $.41^{* *}$ & $.24^{* *}$ & $.28^{* *}$ & $.42^{* *}$ & $.11^{*}$ & $.20^{* *}$ & & \\
\hline 12. Emotional stability & -.01 & $-.45^{* *}$ & $-.54^{* *}$ & $.46^{* *}$ & $.15^{* *}$ & $.22^{* *}$ & $.56^{* *}$ & $.47^{* *}$ & $.36^{* *}$ & $.22^{* *}$ & $.22 * *$ & \\
\hline 13. Openness to experience & -.01 & -.05 & .09 & .02 & $.15^{* *}$ & $.31^{* *}$ & .04 & $.23^{* *}$ & -.04 & .08 & $.30^{* *}$ & $-.12^{*}$ \\
\hline
\end{tabular}

Note: ${ }^{* *} p<.01 .{ }^{*} p<.05$. 
Table 3. Regression Results for the Overall Sample, Boys and Girls.

\begin{tabular}{|c|c|c|c|c|}
\hline & Scales & $\beta$ & SC & RW \\
\hline \multicolumn{5}{|l|}{$\begin{array}{l}\text { Overall } \\
\text { sample }\end{array}$} \\
\hline & Depressive symptoms & $.52^{* *}$ & $.95^{* *}$ & $48.9^{* *}$ \\
\hline & Identity & $-.17^{*}$ & $-.74^{* *}$ & $17.2^{* *}$ \\
\hline & Life satisfaction & $-.12^{*}$ & $-.68^{* *}$ & $15.1^{* *}$ \\
\hline & Emotional stability & -.01 & $-.63^{* *}$ & $10.6^{* *}$ \\
\hline & Conscientiousness & -.03 & $-.29^{*}$ & 2.0 \\
\hline & Extraversion & .04 & $-.29 *$ & 1.8 \\
\hline & Agreeableness & -.01 & -.25 & 1.5 \\
\hline & Self-reliance & -.04 & -.19 & 1.0 \\
\hline & Work orientation & .03 & -.24 & 1.3 \\
\hline & Openness & .03 & .07 & 0.5 \\
\hline \multicolumn{5}{|l|}{ Boys } \\
\hline & Depressive symptoms & $.48^{* *}$ & $.92^{* *}$ & $40.7^{* *}$ \\
\hline & Identity & $-.16^{*}$ & $-.75^{* *}$ & $15.7^{* *}$ \\
\hline & Emotional stability & -.06 & $-.73^{* *}$ & $13.7^{* *}$ \\
\hline & Life satisfaction & -.07 & $-.63^{* *}$ & $10.7^{*}$ \\
\hline & Self-reliance & $-.16^{*}$ & $-.41^{* *}$ & $8.0^{*}$ \\
\hline & Conscientiousness & -.07 & $-.30^{*}$ & 4.6 \\
\hline & Extraversion & -.01 & $-.39 *$ & 3.9 \\
\hline & Work orientation & .03 & -.27 & 1.6 \\
\hline & Agreeableness & .01 & -.22 & 0.9 \\
\hline & Openness & -.01 & -.08 & 0.4 \\
\hline \multicolumn{5}{|l|}{ Girls } \\
\hline & Depressive symptoms & $.51^{* *}$ & $.95^{* *}$ & $48.8^{* *}$ \\
\hline & Life satisfaction & $-.18^{*}$ & $-.69^{* *}$ & $18.6^{* *}$ \\
\hline & Identity & $-.17^{*}$ & $-.71^{* *}$ & $17.1^{* *}$ \\
\hline & Emotional stability & .02 & $-.51^{* *}$ & $7.0^{*}$ \\
\hline & Agreeableness & -.04 & $-.29 *$ & 2.6 \\
\hline & Extraversion & .03 & -.22 & 1.2 \\
\hline & Work orientation & .01 & -.21 & 1.3 \\
\hline & Conscientiousness & .01 & -.23 & 1.1 \\
\hline & Self-reliance & .08 & -.01 & 1.1 \\
\hline & Openness & .03 & .14 & 1.0 \\
\hline
\end{tabular}

Note: The variables are ordered according to their relative weights. SC = Structure coefficient; RW = Relative weight (reported as percentages).

${ }^{* *} p<.01 .{ }^{*} p<.05$.

significantly to the prediction of suicidal ideation. The Johnson's relative weights of the other six variables were not significant, which means that they do not contribute significantly to the prediction of suicidal ideation. The relative contribution to Multiple $\mathrm{R}$ for each predictor was: 48.9 for Depressive symptoms, 17.2 for Identity, 15.1 for Life satisfaction and 10.6 for Emotional stability.

MIMR-Raw.sps was also used to carry out multiple regression analyses for each sex separately. The $R^{2}$ was $.55(F=17.65, p<.001)$ for boys, and the corresponding confidence interval was between .41 and .70 . The $R^{2}$ was $.51(F=20.54, p<.001)$ for girls, and the corresponding confidence interval was between .40 and .64 . As can be seen in Table 3, there were differences in the results found for each sex. With regard to the results found in boys, three predictors (Depressive symptoms, Identity and Self-reliance) turned out to have a significant Beta $(p<.01)$ and also significant structure coefficients. Moreover, the significant Johnson's relative weights of Life satisfaction and Emotional stability suggest that these variables also contribute significantly to the prediction of suicidal ideation in boys, although they do not have significant Beta. However, the Johnson's relative weights of the other five variables were not significant, which means that they do not contribute significantly to the prediction of suicidal ideation. The relative contribution to Multiple R for each predictor was: 40.7 for Depressive symptoms, 15.7 for Identity, 8.0 for Selfreliance, 10.7 for Life satisfaction and 13.7 for Emotional stability. With regard to the results found in girls, the following three predictors showed significant Beta $(p<.01)$ and significant structure coefficients: Depressive symptoms, Life satisfaction and Identity. Moreover, the significant Johnson's relative weights of Emotional stability suggest that this variable also contributes significantly to the prediction of suicidal ideation in girls, although its Beta was not significant. The Johnson's relative weights of the other six variables were not significant, which means that they do not contribute significantly to the prediction of suicidal ideation. The relative contribution to Multiple $\mathrm{R}$ for each predictor was: 48.8 for Depressive symptoms, 18.6 for Life satisfaction, 17.1 for Identity and 7.0 for Emotional stability.

Finally, two Multigroup Structural Equation Models were proposed to better understand the relationships between these variables for each sex. Figure 1 shows the first model that we tested, which includes the following variables: Emotional stability, Depressive symptoms, Life satisfaction, Identity and suicidal ideation. As we explained above, several studies show that a high level of Emotional stability facilitates Identity formation, and it is also related to lower levels of Depression and higher levels of Life satisfaction (Heisel \& Flett, 2004; Klimstra et al., 2013, MoralesVives et al., 2013). Moreover, other studies show that Depression is related to Identity and Life satisfaction (Heisel \& Flett, 2004; Schwartz et al., 2011). These relationships were included in this model. Moreover, we expected to find an indirect relationship between Emotional stability and Suicidal ideation, through its relationship with Depressive symptoms, Identity, Life satisfaction, so this indirect relationship was also tested in this model. The fit of the model was almost perfect which is partly due to the model's limited number of degrees of freedom: the $\chi^{2}(2)$ was 1.939 , which agrees with the expected value under the null hypothesis. As a consequence, the remaining fit indices were 


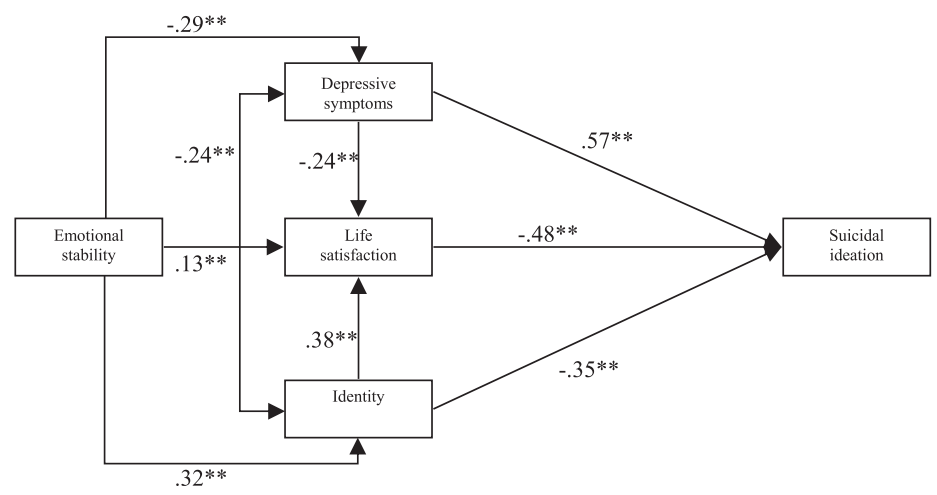

Figure 1. First model in the prediction of suicidal ideation.

exceedingly good: $\mathrm{CFI}=1.000, \mathrm{TLI}=1.001, \mathrm{RMSEA}=.000$ and SRMR $=.009$. Therefore, these fit indices indicate that the hypothesized model fits the data satisfactory well for each of the two groups. The chi-square contributions were 0.288 for girls and 1.650 for boys. Therefore, despite the excellent overall fit of the model, it appears that the fit is better for girls than for boys. Regarding the relationship between Emotional stability and Suicidal ideation, if we include in the model the path between these variables, the path is close to zero and not significant ( $p=.559)$, which also shows the indirect relationship between these variables.

Figure 2 shows the second model tested, which includes the same variables as before plus Self-reliance (this variable was significant for boys in the multiple regression analyses). The values obtained for the indices of fit were: CFI $=0.995$, TLI $=0.973$, RMSEA $=.062$ (confidence intervals range from .125 to .00), SRMR = .034. Results higher than 0.95 for CFI and TLI, and results close to zero for RMSEA and SRMR, suggest a good fit, so these results suggest that the fit for this model is also acceptable for each of the two groups. The $\chi^{2}(6)$ was $10.154(p>.05)$, and the contribution of each sex to the $\chi^{2}$ was 8.175 for girls and 1.978 for boys. Therefore, although the second model acceptably fits in both groups, the fit seems to be better for boys. It could be argued that these differences in the contribution of $\chi^{2}$ for boys and girls to both models are due to the lack of gender-related invariance in some parameters. However, the low values of the modification indices suggested that both models were essentially invariant. Regarding the relationship between Emotional stability and Suicidal ideation, if we include in the model the path between these variables, the path is close to zero and not significant ( $p=.625)$, which also shows the indirect relationship between these variables.

\section{Discussion}

The main aim of the current study was to assess the relative importance of personality, depression, life satisfaction and psychological maturity to predict suicidal ideation in adolescents. The results show that the main predictor is depressive symptoms, which is consistent with previous studies (e.g., Allison et al., 2001; Lasgaard et al., 2011). Regarding the Big five personality traits, only emotional stability is a predictor of suicidal ideation.

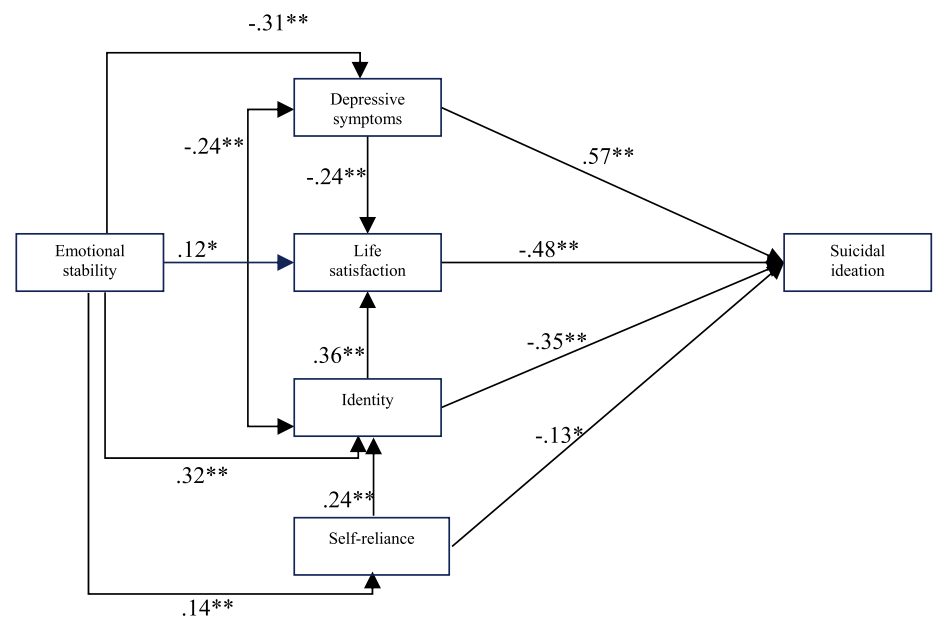

Figure 2. Second model in the prediction of suicidal ideation. 
This result agrees with the earlier finding by Chioqueta and Stiles (2005), although other studies found that Extraversion is a significant predictor of suicidal ideation as well (e.g., DeShong et al., 2015). However, the fact that some of these previous studies did not control the effect of depression could lead to misleading results (De Man \& Leduc, 1995). The Multigroup Structural Equation Models analyses carried out show that emotional stability has an indirect relationship with suicidal ideation, through its relationship with depressive symptoms, life satisfaction and identity, as it was expected. The study done by Vrshek-Schallhorn et al. (2011) also suggested that emotional stability has an indirect relationship with suicidal ideation, through its relationship with depression. However, in the current study we expected that this indirect relationship could also be explained through the relationship of this personality trait with the rest of variables. Previous studies show that a high level of emotional stability facilitates identity formation (Klimstra et al., 2013; Morales-Vives et al., 2013), and it is related with lower levels of depression and higher levels of life satisfaction (Heisel \& Flett, 2004). Therefore, the results of the current study suggest that those adolescents with less emotional stability would tend to feel less life satisfaction and more depressive symptoms, and also have a less coherent sense of personal identity, which in turn would facilitate greater suicidal ideation.

The relationship between suicidal ideation and life satisfaction has been subject to little study. However, some studies show that subjective wellbeing is a predictor of suicidal ideation in adolescents (e.g., Park et al., 2005) and adults (e.g., Amer \& Hamdan-Mansour, 2014; Koivumaa-Honkanen et al., 2001). Life satisfaction is the cognitive component of subjective wellbeing; therefore, we expected to find a significant relationship between life satisfaction and suicidal ideation. In fact, the results show that it is a predictor of suicidal ideation. It is important to point out that life satisfaction decreases during adolescence (Goldbeck et al., 2007), possibly due to the stress generated by the physical and emotional changes of this developmental stage. Thus, adolescents tend to make more negative global assessments of their own lives than in other life stages, which in turn might explain this relationship with suicidal ideation. Moreover, the Multigroup Structural Equation Models analyses show that lower levels of identity and emotional stability, and higher levels of depressive symptoms, would lead to lower levels of life satisfaction, which would facilitate greater suicidal ideation. These results support the assertion of Heisel and Flett (2004) regarding the importance of including positive psychological factors in the prediction of suicidal ideation, and not only negative psychological factors.
Regarding the gender differences, the results suggest that emotional stability, depression, life satisfaction and identity are predictors of suicidal ideation for both boys and girls, as it was expected. Previous studies also show that depressive symptoms, emotional stability and life satisfaction are predictors of suicidal ideation for both genders (Valois et al., 2004; Wannan \& Fombonne, 1998). The results obtained from the psychological maturity subscales suggest that identity is a predictor of suicidal ideation in boys and girls, but Self-reliance is a better predictor for boys than for girls. Therefore, previous studies show that some suicidal ideation predictors are not the same for both genders (e.g., Allison et al., 2001; Park et al., 2005), although there are no previous studies about psychological maturity in adolescents. The results of the current study suggest that boys with less self-knowledge, less autonomy and less initiative tend to have higher levels of suicidal ideation, although the level of autonomy and initiative does not seem so relevant to predicting suicidal ideation in females. These results support the assertion of Portes, Sandhu, and Longwell-Grice (2002) that there is relationship between autonomy and psychological adjustment of adolescents. According to these authors, failure to establish autonomy leaves the individual subject to insecurity and doubt, which can lead to externalizing and internalizing problems. Further research is necessary to explain the reason for these differences between genders, which might be a result of sociocultural influences or biological and developmental factors. The results obtained in the two Multigroup Structural Equation Models tested (the first one did not include Self-reliance, but the second one did) suggest that both models fit well for boys and girls. However, the first model fits better for girls and the second model fits better for boys. Therefore, we consider that the second model, which includes Selfreliance, is preferable to the first model, because it includes all the relevant predictors for boys, and more completely identifies the variables that can facilitate suicidal ideation in boys. Moreover, the inclusion of this variable does not mean that the model is no longer appropriate for girls, since the model fit is good for both sexes. Regarding the subscale Work orientation, the results suggest that it is not a relevant predictor of suicidal ideation. Likewise, the personality trait Conscientiousness, which is related to some extent to Work orientation (Morales-Vives et al., 2013), is not a relevant predictor either, which is consistent with previous studies (Chioqueta \& Stiles, 2005; Kerby, 2003).

As the Multigroup Structural Equation Models show, there is a relationship between identity and depressive symptoms. In fact, Schwartz et al. (2011) found that day-to-day fluctuations in identity predicted subsequent anxiety and depression. Likewise, Schwartz 
(2007) pointed out that a coherent sense of personal identity protects against indicators of distress such as anxiety and depression. However, the results we found in the Multigroup Structural Equation Models suggest that the relationship between these variables is reciprocal. Therefore, depression can also interfere in the development of identity. According to Klimstra et al. (2013) identity is also related to emotional stability, as we have found in the current study. More specifically, low emotional stability may also interfere in the development of identity.

Understanding which factors are related to suicidal phenomena might help to identify those adolescents who are predisposed to showing suicidal behaviors. The current research provides new evidence about these factors, particularly in relation to psychological maturity. There have been no previous studies on the role of psychological maturity as a predictor of suicidal phenomena, but the current study suggests that psychological maturity is a feature to be considered in the prediction of adolescent suicidal ideation. Moreover, this study also helps to understand the role of emotional stability in the prediction of suicidal ideation. Regarding the limitations of this study, we have used a cross-sectional design, so further longitudinal and sequential studies are needed to broaden the perspective on the relationship between these variables, and their evolution throughout adolescence. Another limitation of this study is that only self-report measures were used to assess the variables, so further studies are needed to determine if the results are the same with different measures, such as interviews. Moreover, the current research was carried out with a general community sample, so further research is also required to determine if these results are replicated in clinical samples, and more specifically to assess whether psychological maturity is also related to suicidal behavior.

As Evans, Hawton, and Rodham (2004) pointed out, identifying factors associated with suicidal phenomena may play an important role in school or communitybased prevention and intervention programs. The results of the current study suggest that these prevention programs should include activities to help adolescents explore and develop their identity, as well as other activities to increase personal coping strategies and the management of emotions. These activities would help adolescents achieve greater emotional stability, which in turn would increase their life satisfaction and decrease their depressive symptomatology, thus reducing suicidal ideation. Moreover, according to the results of this study, these programs should also include some activities for parents so they can learn how to encourage the progressive autonomy of children.

\section{References}

Allison S., Roeger L., Martin G., \& Keeves J. (2001). Gender differences in the relationship between depression and suicidal ideation in young adolescents. Australian \& New Zealand Journal of Psychiatry, 35(4), 498-503. https:/ /doi. org/10.1046/j.1440-1614.2001.00927.x

Amer N. R. Y., \& Hamdan-Mansour A. M. (2014). Psychosocial predictors of suicidal ideation in patients diagnosed with chronic illnesses in Jordan. Issues in Mental Health Nursing, 35(11), 864-871. https:/ / doi.org/10.3109/ 01612840.2014.917752

Beck A. T., Kovacs M., \& Weissman A. (1979). Assessment of suicidal intention: The Scale for Suicide Ideation. Journal of Consulting and Clinical Psychology, 47(2), 343-352. https: / / doi.org/10.1037/0022-006X.47.2.343

Beck A. T., Ward C. H., Mendelson M., Mock J., \& Erbaugh J. (1961). An inventory for measuring depression. Archives of General Psychiatry, 561-571. https://doi.org/10.1001/ archpsyc.1961.01710120031004

Cauffman E., \& Steinberg L. (2000). (Im)maturity of judgment in adolescence: Why adolescents may be less culpable than adults. Behavioral Sciences \& the Law, 18, 741-760. https://doi.org/10.1002/bsl.416

Chioqueta A. P., \& Stiles T. C. (2005). Personality traits and the development of depression, hopelessness, and suicide ideation. Personality and Individual Differences, 38(6), 1283-1291. https://doi.org/10.1016/j.paid.2004.08.010

Christiansen C. H., Backman C., Little B. R., \& Nguyen A. (1999). Occupations and well-being: A study of personal projects. The American Journal of Occupational Therapy, 53(1), 91-100. https://doi.org/10.5014/ajot.53.1.91

De Man A. F., \& Leduc C. P. (1995). Suicidal ideation in high school students: Depression and other correlates. Journal of Clinical Psychology, 51(2), 173-181. https:/ / doi.org/ 10.1002/1097-4679(199503)51:2<173::AIDJCLP2270510205>3.0.CO;2-R

DeShong H. L., Tucker R. P., O'Keefe V. M., MullinsSweatt S. N., \& Wingate L. R. (2015). Five factor model traits as a predictor of suicide ideation and interpersonal suicide risk in a college sample. Psychiatry Research, 226(1), 217-223. https:/ / doi.org/10.1016/j.psychres.2015.01.002

Diener E., Emmons R. A., Larsen R. J., \& Griffin S. (1985). The satisfaction with life scale. Journal of Personality Assessment, 49, 71-75. https://doi.org/10.1207/ s15327752jpa4901_13

Erroteta J. M., \& Rodrigo I. (2013). Afectividad. In I. Eguiluz \& R. Segarra (Eds.), Introducción a la psicopatología. Una visión actualizada [Introduction to psychopathology. An updated vision] (pp. 115-159). Madrid, Spain: Editorial Médica Panamericana.

Evans E., Hawton K., \& Rodham K. (2004). Factors associated with suicidal phenomena in adolescents: A systematic review of population-based studies. Clinical Psychology Review, 24(8), 957-979. https:/ / doi.org/10.1016/j.cpr.2004.04.005

Fergusson D. M., Woodward L. J., \& Horwood L. J. (2000). Risk factors and life processes associated with the onset of suicidal behavior during adolescence and early adulthood. Psychological Medicine, 30(01), 23-39. https:/ / doi. org/10.1017/S003329179900135X 
Ferrando P. J., Lorenzo-Seva U., \& Chico E. (2009). A general factor-analytic procedure for assessing response bias in questionnaire measures. Structural Equation Modeling, 16(2), 364-381. https:/ / doi.org/10.1080/10705510902751374

Goldbeck L., Schmitz T. G., Besier T., Herschbach P., \& Henrich G. (2007). Life satisfaction decreases during adolescence. Quality of Life Research, 16(6), 969-979. https://doi.org/10.1007/s11136-007-9205-5

Greenberger E. (1984). Defining psychosocial maturity in adolescence. Advances in Child Behavioral Analysis \& Therapy, 3, 1-37.

Heisel M. J., Duberstein P. R., Conner K. R., Franus N., Beckman A., \& Conwell Y. (2006). Personality and reports of suicide ideation among depressed adults 50 years of age or older. Journal of Affective Disorders, 90(2-3), 175-180. https://doi.org/10.1016/j.jad.2005.11.005

Heisel M. J., \& Flett G. L. (2004). Purpose in life, satisfaction with life, and suicide ideation in a clinical sample. Journal of Psychopathology and Behavioral Assessment, 26(2), 127-135. https://doi.org/10.1023/B:JOBA. 0000013660.22413.e0

Hills P., \& Argyle M. (2001). Emotional stability as a major dimension of happiness. Personality and Individual Differences, 31(8), 1357-1364. https:/ / doi.org/10.1016/ S0191-8869(00)00229-4

Hintikka J., Koivumaa-Honkanen H., Lehto S. M., Tolmunen T., Honkalampi K., Haatainen K., \& Viinamäki H. (2009). Are factors associated with suicidal ideation true risk factors? A 3-year prospective follow-up study in a general population. Social Psychiatry and Psychiatric Epidemiology, 44(1), 29-33. https: / /doi.org/ 10.1007/s00127-008-0401-6

Hu L. T., \& Bentler P. M. (1999). Cutoff criteria for fit indexes in covariance structure analysis: Conventional criteria versus new alternatives. Structural Equation Modeling: A Multidisciplinary Journal, 6(1), 1-55. https:/ / doi.org/ 10.1080/10705519909540118

Inder K. J., Handley T. E., Johnston A., Weaver N., Coleman C., Lewin T. J., ... \& Kelly B. J. (2014). Determinants of suicidal ideation and suicide attempts: Parallel cross-sectional analyses examining geographical location. BMC Psychiatry, 14, 1-20. https:/ /doi.org/ 10.1186/1471-244X-14-208

Johnson J. W. (2000). A heuristic method for estimating the relative weight of predictor variables in multiple regression. Multivariate Behavioral Research, 35(1), 1-19. https://doi.org/10.1207/S15327906MBR3501_1

Kandel D. B., Raveis V. H., \& Davies M. (1991). Suicidal ideation in adolescence: Depression, substance use, and other risk factors. Journal of Youth and Adolescence, 20(2), 289-309. https: / / doi.org/10.1007/BF01537613

Kelly T. M., Lynch K. G., Donovan J. E., \& Clark D. B. (2001). Alcohol use disorders and risk factor interactions for adolescent suicidal ideation and attempts. Suicide $\mathcal{E}$ Life-Threatening Behavior, 31, 181-193. https://doi. org/10.1521/suli.31.2.181.21512

Kerby D. S. (2003). CART analysis with unit-weighted regression to predict suicidal ideation from Big Five traits. Personality and Individual Differences, 35(2), 249-261. https://doi.org/10.1016/S0191-8869(02)00174-5
Klimstra T. A., Akse J., Hale III, W. W., Raaijmakers Q. A. M., \& Meeus W. H. J. (2010). Longitudinal associations between personality traits and problem behavior symptoms in adolescence. Journal of Research in Personality, 44(2), 273-284. https:/ / doi.org/10.1016/ j.jrp.2010.02.004

Klimstra T. A., Luyckx K., Goossens L., Teppers E., \& De Fruyt F. (2013). Associations of identity dimensions with Big Five personality domains and facets. European Journal of Personality, 27, 213-221. https:/ / doi.org/ 10.1002/per.1853

Koivumaa-Honkanen H., Honkanen R., Viinamäki H., Heikkilä K., Kaprio J., \& Koskenvuo M. (2001). Life satisfaction and suicide: A 20-year follow-up study. The American Journal of Psychiatry,158, 433-439. https:/ / doi. org/10.1176/appi.ajp.158.3.433

Kotov R., Gamez W., Schmidt F., \& Watson D. (2010). Linking "big" personality traits to anxiety, depressive, and substance use disorders: A meta-analysis. Psychological Bulletin, 136(5), 768-821. https:/ / doi.org/10.1037/ a0020327

Lasgaard M., Goossens L., \& Elklit A. (2011). Loneliness, depressive symptomatology, and suicide ideation in adolescence: Cross-sectional and longitudinal analyses. Journal of Abnormal Child Psychology, 39(1), 137-150. https://doi.org/10.1007/s10802-010-9442-x

Lorenzo-Seva U., \& Ferrando P. J. (2009). Acquiescent responding in partially balanced multidimensional scales. British Journal of Mathematical and Statistical Psychology, 62, 319-326. https://doi.org/10.1348/000711007X265164

Lorenzo-Seva U., Ferrando P. J., \& Chico E. (2010). Two SPSS programs for interpreting multiple regression results. Behavior Research Methods, 42(1), 29-35. https: / / doi.org/ 10.3758/BRM.42.1.29

Marsh H. W., Morin A. J. S., Parker P. D., \& Kaur G. (2014). Exploratory structural equation modeling: An integration of the best features of exploratory and confirmatory factor analysis. Annual Review of Clinical Psychology, 10, 85-110. https://doi.org/10.1146/annurev-clinpsy-032813-153700

Miranda R., Ortin A., Scott M., \& Shaffer D. (2014). Characteristics of suicidal ideation that predict the transition to future suicide attempts in adolescents. Journal of Child Psychology and Psychiatry, 55(11), 1288-1296. https://doi.org/10.1111/jcpp.12245

Morales-Vives F., Camps E., \& Lorenzo-Seva U. (2013). Development and validation of the Psychosocial Maturity Assessment Scale (PSYMAS). European Journal of Psychological Assessment, 29(1), 12-18. https:/ / doi.org/ 10.1027/1015-5759/a000115

Nock M. K., Borges G., Bromet E. J., Cha C. B., Kessler R. C., \& Lee S. (2008). Suicide and suicidal behavior. Epidemiological Review, 30, 133-154. https:/ / doi. org/10.1093/epirev/mxn002

Park H., Koo H., \& Schepp K. (2005). Predictors of suicidal ideation for adolescents by gender. Taehan Kanho Hakhoe Chi, 35(8), 1433-1442. https://doi.org/10.4040/jkan. 2005.35.8.1433

Park S. (2013). Predictors of suicidal ideation in late childhood and adolescence: A 5 year follow up of two nationally representative cohorts in the Republic of Korea. 
Suicide and Life-Threatening Behavior, 43(1), 81-96. https:/ / doi.org/10.1111/j.1943-278X.2012.00129.x

Pfeffer C. R., Lipkins R., Plutchik R., \& Mizruchi M. (1988). Normal children at risk for suicidal behavior: A two-year follow-up study. Journal of The American Academy of Child and Adolescent Psychiatry, 27(1), 34-41. https://doi.org/ 10.1097/00004583-198801000-00006

Pitman A., Krysinska K., Osborn D., \& King M. (2012). Suicide in young men. The Lancet, 379(9,834), 2383-2392. https://doi.org/10.1016/S0140-6736(12)60731-4

Portes P. R., Sandhu D. S., \& Longwell-Grice R. (2002). Understanding adolescent suicide: A psychosocial interpretation of developmental and contextual factors. Adolescence, 37(148), 805.

Schimmack U., Schupp J., \& Wagner G. G. (2008). The influence of environment and personality on the affective and cognitive component of subjective well-being. Social Indicators Research, 89(1), 41-60. https: / doi.org/10.1007/ s11205-007-9230-3

Schwartz S. J. (2007). The structure of identity consolidation: Multiple correlated constructs or one superordinate construct? Identity: An International Journal of Theory and Research, 7(1), 27-49. https://doi.org/10.1080/ 15283480701319583

Schwartz S. J., Klimstra T. A., Luyckx K., Hale III, W. W., Frijns T., Oosterwegel A., ... \& Meeus W. H. J. (2011). Daily dynamics of personal identity and self-concept clarity. European Journal of Personality, 25(5), 373-385. https:/ / doi.org/10.1002/per.798

Sood S., \& Gupta R. (2014). Subjective happiness as mediator between personal growth initiative and life satisfaction in adolescents. International Journal of Psychological Studies, 6(4), 89. https://doi.org/10.5539/ijps.v6n4p89

Steiger J. H. (2007). Understanding the limitations of global fit assessment in structural equation modeling. Personality and Individual Differences, 42(5), 893-898. https: / / doi.org/ 10.1016/j.paid.2006.09.017
Valois R. F., Zullig K. J., Huebner E. S., \& Drane J. W. (2004). Life satisfaction and suicide among high school adolescents. Social Indicators Research, 66(1-2), 81-105. https://doi.org/10.1023/B:SOCI.0000007499.19430.2f

Valois R. F., Zullig K. J., \& Hunter A. A. (2015). Association between adolescent suicide ideation, suicide attempts and emotional self-efficacy. Journal of Child and Family Studies, 24(2), 237-248. https:/ / doi.org/10.1007/s10826-013-9829-8

Velting D. M. (1999). Suicidal ideation and the five-factor model of personality. Personality and Individual Differences, 27(5), 943-952. https:/ / doi.org/10.1016/S01918869(99)00046-X

Vigil-Colet A., Morales-Vives F., Camps E., Tous J., \& Lorenzo-Seva U. (2013). Development and validation of the Overall Personality Assessment Scale (OPERAS). Psicothema, 25(1), 100-106. https://doi.org/10.7334/ psicothema2011.411

Villardón L. (1993). El pensamiento de suicidio en la adolescencia [The thought of suicide in adolescence]. Bilbao, Spain: Rontegui.

Viñas F., Canals J., Gras M., Ros C., \& Domènech-Llaberia E. (2002). Psychological and family factors associated with suicidal ideation in pre-adolescents. The Spanish Journal of Psychology, 5(01), 20-28.

Vrshek-Schallhorn S., Czarlinski J., Mineka S., Zinbarg R. E., \& Craske M. (2011). Prospective predictors of suicidal ideation during depressive episodes among older adolescents and young adults. Personality and Individual Differences, 50(8), 1202-1207. https:/ / doi.org/10.1016/ j.paid.2011.02.008

Wannan G., \& Fombonne E. (1998). Gender differences in rates and correlates of suicidal behavior amongst child psychiatric outpatients. Journal of Adolescence, 21(4), 371-381. https://doi.org/10.1006/jado.1998.0162

World Health Organization (2012). Public health action for the prevention of suicide: A framework. Geneva, Switzerland: Author. 